\title{
Novel osteogenic factors prevents osteoporosis in obese type 2 diabetes
}

\author{
Masayoshi Yamaguchi* \\ Department of Hematology and Medical Oncology, Emory University School of Medicine, Atlanta, GA, USA
}

Bone is a dynamic tissue that undergoes continual adaptation during vertebrate life to attain and preserves skeletal size, shape and structural integrity and to regulate mineral homeostasis. Bone homeostasis, which maintains bone mass, is skillfully regulated through a delicate balance between osteoblastic bone formation and osteoclastic bone resorption [1-3]. Osteoblasts are differentiated from bone marrow mesenchymal stem cells and stimulate bone formation and calcification. Osteoclasts are developed from hematopoietic progenitors and promote bone resorption. Physiologic process of bone turnover through these bone cells underpins development and maintenance of the skeletal system. Bone remodeling and modeling underpin development and maintenance of the skeletal system [1] Bone modeling is responsible for growth and mechanically induced adaptation of bone, and it requires that the processes of bone formation and bone removal (resorption). Process of bone remodeling that makes bone unique among organs and tissues, and add so many levels of complexity with respect to interactions along remodeling sequence by systemic influences (hormones), stress action (physical activity/weight bearing), and growth factors and cytokines produced by the bone cells or factors that come from nearby cells in the marrow tissues.

Numerous pathological processes have the capacity to disrupt this equilibrium by leading to conditions where the rate of bone resorption outpaces and the rate of bone formation, leading to osteoporosis [4]. Osteoporosis is a disease characterized by loss in bone density and bone strength and deterioration of bone microarchitecture, resulting in increased risk for bone fractures. The most dramatic expression of osteoporosis is represented by fractures of the proximal femur for which the number increases as the population ages [4]. Osteoporosis is a common metabolic disease and generally affects people at an advanced age and suffering from other chronic diseases. It is more common in women and a significant loss of bone mass after menopause begins. Bone mass is dramatically reduced after menopause, which depresses secretion of ovarian hormone (estrogen) in women [4]. Deficiency of estrogen advances osteoclastic bone resorption. This is very important as a primary osteoporosis. Postmenopausal osteoporosis is the archetypal osteoporotic condition in women after menopause and leads to bone destruction through complex and diverse metabolic and biochemical changes.

Osteoporosis is a major cause of increased morbidity and mortality affecting the aging population. It has been estimated that osteoporosis affects at least 200 million women worldwide, one third of women aged between 60 and 70 years and two thirds over 80 years [5,6]. In 1995, incidence of osteoporotic fractures in the U.S. was about 1.5 million, of which 750000 vertebral fractures, 250,000 hip fractures, 250,000 fractures in the wrist fracture and 250000 other locations. According to a recent World Health Organization report, osteoporosis has become a global health problem with a disease incidence and mortality rate similar to that of cardiovascular diseases, diabetes and cancer [7-10]. Osteoporosisis is widely recognized as a major public health threat.

Currently, obesity and diabetes are a major health problem worldwide and are growing in prevalence in the U.S. Osteoporosis associated with obesity and diabetes has also been noticed $[8,9]$. Diabetes is frequent in the elderly and therefore frequently coexists with osteoporosis. The incidence of metabolic disease, including obesity and obese type 2 diabetes, has increased to epidemic levels in recent years [9]. Osteoporosis and obesity are now thought to be closely related and to share several features. Low body weight has long been recognized as a risk factor for fracture in the elderly. Attention has only recently turned to fractures in overweight or obese individuals. In Western societies, mean body weight has increased dramatically in older people, and a similar trend exists in Asia. One of these shared features is that osteoblasts and adipocytes differentiate from a common precursor cell in the bone marrow, the mesenchymal stem cell. The pluripotency of mesenchymal stem cells is well known, and their ability to differentiate into osteoblasts, adipocytes, chondrocytes and myoblasts has been described extensively [11-16]. There is an inverse relationship between differentiation of mesenchymal stem cells to osteoblasts and adipocytes. Secondary causes of osteoporosis including obesity and diabetes are associated with bone marrow adiposity, which greatly produces tumor necrosis factor- $\alpha$ (TNF- $\alpha$ ), an inflammatory cytokine [17-19]. TNF- $\alpha$ is found to suppress osteoblastogenesis and mineralization $[20,21]$.

Bone marrow mesenchymal stem cells are multipotent cells, which among other cell lineages, give rise to adipocytes and osteoblasts. Bone marrow mesenchymal stem cells are multipotent stromal cells, which among other cell lineages, that can differentiate into a variety of cell types including osteoblasts (bone cells), chondrocytes (cartilage cells), myoblasts (heart cells) and adipocytes (fat cells) [11,12]. This occurs through cross talk between complex signaling pathways including those derived from bone morphogenic proteins (BMPs), wingless type MMTV integration site (Wnt) proteins, hedgehogs, delta/jagged proteins, fibroblastic growth factors, insulin, insulin-like growth factors, and transcriptional regulators of adipocyte and osteoblast differentiation including peroxisome proliferators-activated receptor-

Correspondence to: Masayoshi Yamaguchi, Department of Hematology and Medical Oncology, Emory University School of Medicine, 1365 C Clifton Road NE, Atlanta, GA 30322, USA; E-mail: yamamasa1155@yahoo.co.jp

Received: February 28, 2015; Accepted: March 13, 2015; Published: March 16, 2015 
gamma (PPAR $\gamma)$ and runt-related transcription factor 2 (Runx2) [1416]. Differentiation of bone marrow mesenchymal stem cells may be involved in the development of osteoporosis.

For example, regucalcin has been found to stimulate adipogenesis and suppress osteoblastogenesis in mouse bone marrow culture systems in vitro [22]. Interestingly, bone loss and hyperlipidemia have been shown to induce in regucalcin transgenic rats [23]. These findings suggest that development of osteoporosis is strongly involved in the regulation of differentiation of bone marrow mesenchymal stem cells. Moreover, biofactors, which regulate the differentiation of bone marrow mesenchymal stem cells, may have preventive effects on bone loss in obesity and diabetes [24,25]. This finding may be significant to develop new drugs for the treatment of osteoporosis with obesity and diabetes. Functional food and botanical factors, which have an effect on osteoblastogenesis and adipogenesis, may reveal preventive and treatment effects on bone loss associated with obese type 2 diabetes. Such factors, however, are poorly understood.

Cinnamic acid, a flavonoid, is present in many plant and fruits. The flavonoid $p$-hydroxycinnamic acid (HCA) is an intermediatemetabolic substance in plant and fruits, and it is synthesized from tyrosine. Among cinnamic acid and its related compounds (cinnamic acid, HCA, ferulic acid, caffeic acid and 3, 4-dimethoxycinnamic acid), HCA has been shown to have specific-anabolic effects on bone in vitro [26]. HCA was found to stimulate osteoblastic bone formation and to inhibit osteoclastic bone resorption in vitro [27,28]. HCA stimulated osteoblastogenesis and inhibited osteoclastogenesis through suppressing of NF- $\kappa B$ signaling, which was activated by TNF- $\alpha$ or the receptor activator of nuclear factor-kappa $B$ ligand (RANKL) stimulation $[29,30]$, suggesting a molecular mechanism by which HCA has an anabolic effect on bone. Moreover, HCA revealed preventive and restorative effects on ovariectomy-induced bone loss of rats in vivo [31]. Thus, HCA, a new osteogenic factor, has been found to prevent osteoporosis.

Interestingly, oral administration of HCA has preventive and restorative effects on hyperglycemia, hyperlipidemia and bone loss in type 1 diabetic rats induced by treatment with streptozotocin in vivo [32], demonstrating that HCA reveals preventive and restorative effects on diabetic states. Chemical compound, which prevents diabetic bone loss, has not been reported thus far. Moreover, HCA has been shown to stimulate osteoblastogenesis and suppresse adipogenesis using culture systems with mouse bone marrow cells and mouse 3T3-L1 preadipocytes in vitro [22]. Bioactive flavonoid HCA, a novel osteogenic factor, may reveal preventive and therapeutic effects on osteoporosis associated with obese type 2 diabetes.

Anti-resorptive agents have been used the preferred standard of clinical care for the amelioration of bone loss in osteoporosis. However, clinical compounds that stimulate bone formation are under development. Novel analogues, which are synthesized from bioactive chemicals derived from food factors, may be developed as new drugs that reveal potent-osteogenic effects for the treatment of osteolysis, which is induced in various diseases including inflammation, obesity and diabetes. Development of osteogenic factors, which target the differentiation of bone marrow mesenchymal stem cells, may be importance in biomedical osteoporosis treatment.

\section{References}

1. Raggatt LJ, Partridge NC (2010) Cellular and molecular mechanismsof bone modeling. J Biol Chem 85: 25103-25108. [Crossref]
2. Chambers TJ, Fuller K (2011) How are osteoclasts induced to resorbbone? Ann N Y Acad Sci 1240: 1-6. [Crossref]

3. Chen G, Deng C, Li YP (2012) TGF- $\beta$ and BMP signaling inosteoblast differentiation and bone formation. Int J Biol Sci 8: 272-288. [Crossref]

4. Weitzmann MN, Pacifici R (2006) Estrogen deficiency and bone loss: an inflammatory tale. J Clin Invest 116: 1186-1194. [Crossref]

5. Johnell O, Kanis JA (2006) An estimate of the worldwide prevalence and disability associated with osteoporotic fractures. Osteoporos Int 17: 1726-1733. [Crossref]

6. Pitts CJ, Kearns AE (2011) Update on medications with adverse skeletal effects. Mayo Clin Proc 86: 338-343. [Crossref]

7. Walker-Bone K (2012) Recognizing and treating secondary osteoporosis. Nat Rev Rheumatol 28: 480-492. [Crossref]

8. Leslie WD, Rubin MR, Schwartz AV, Kanis JA (2012) Type 2 diabetes and bone. $J$ Bone Miner Res 27: 2231-2237. [Crossref]

9. Nielson CM, Srikanth P, Orwoll ES (2012) Obesity and fracture inmen and women: An epidemiologic perspective. J Bone Miner Res 27: 1-10. [Crossref]

10. Weilbaecher KN, Guise TA, McCauley LK (2011) Cancer to bone: a fatal attraction Nature Review 11: 411-425. [Crossref]

11. Minguel JJ, Erices A, Conget P (2001) Mesenchymal stem cells. Exp Biol Med 226 507-520.

12. Muruganandan S, Roman AA, Sinal CJ (2009) Adipocyte differentiation of bone marrow-derived mesenchymal stem cells:cross talk with the osteoblastogenesis program. Cell Mol Life Sci 66: 236-253. [Crossref]

13. Laudes M (2011) Role of WNT signaling in the determination of human mesenchymal stem cells into preadipocytes. J Mol Endocrinol 46: R65-R72. [Crossref]

14. Gharibi B, Abraham AA, Ham J, Evans BA (2011) Adenosine receptor subtype expression and activation influence the differentiation of mesenchymal stem cells to osteoblasts and adipocytes. J Bone Miner Res 26: 2112-2124. [Crossref]

15. Kawai M, Rosen CJ (2010) PPAR $\gamma$ : a circadian transcription factor in adipogenesis and osteogenesis. Nat Rev Endocrinol 6: 629-636. [Crossref]

16. Wu L, Cai X, Dong H, Jing W, Huang Y, et al.(2010) Serum regulates adipogenesis of mesenchymal stem cells via MEK/ERK-dependent PPAR $\gamma$ expression and phosphorylation. J Cell Mol Med 14: 922-932. [Crossref]

17. Parhami F, Tintut Y, Beamer WG, Gharavi N, Goodman W, et al. (2001) Atherogenic high-fat diet reduces bone mineralization in mice. $J$ Bone Miner Res 16: 182-188. [Crossref]

18. Pirih F, Lu J, Ye F, Bezouglaia O, Atti E, et al. (2012) Adverse effects of hyperlipidemia on bone regeneration and strength. J Bone Miner Res 27: 309-318. [Crossref]

19. Cortez M, Carmo LS, Rogero MM, Borelli P, Fock RA (2013) A high-fat diet increases IL-1, IL- 6 , and TNF- $\alpha$ production by increasing NF- $\mathrm{KB}$ and attenuating PPAR- $\gamma$ expression in bone marrow mesenchymal stem cells. Inflammation 36: 379-386. [Crossref]

20. Li Y, Li A, Strait K, Zhang H, Nanes MS, et al. (2007) Endogenous TNF- $\alpha$ lowers maximum peak bone mass and inhibits osteoblastic Smad activation, through NF- $\mathrm{kB} . J$ Bone Miner Res 22: 646-655. [Crossref]

21. Chang J, Wang Z, Tang E, Fan Z, McCauley L, et al. (2009) Inhibition of osteoblastic bone formation by nuclear factor-kB. Nat Med 15: 682-689. [Crossref]

22. Yamaguchi M, Weitzmann MN, Baile CA, Murata T (2012) Exogenous regucalcin suppresses osteoblastogenesis and adipogenesis in mouse bone marrow culture. Integr Biol (Camb) 4: 1215-1222. [Crossref]

23. Yamaguchi M (2010) Regucalcin and metabolic disorder: osteoporosis and hyperlipidemia are induced in regucalcin transgenic rats. Mol Cell Biochem 341: 119133. [Crossref]

24. Lai YL, Yamaguchi M (2006) Phytocomponent $p$-hydroxycinnamic acid stimulates bone formation and inhibits bone resorption in rat femoral tissues in vitro. Mol Cell Biochem 292: 45-52. [Crossref]

25. Yamaguchi M, Baile CA, Zhu S, Shoji M (2013) Bioactive flavonoid $p$-hydroxycinnamic acid stimulates osteoblastogenesis and suppresses adipogenesis in bone marrow culture. Cell Tissue Res 354: 743-750. [Crossref]

26. Lai YL, Yamaguchi M (2006) Phytocomponent $p$-hydroxycinnamic acid stimulates bone formation and inhibits bone resorption in rat femoral tissues in vitro. Mol Cell Biochem 292: 45-52. [Crossref] 
27. Yamaguchi M, Lai YL, Uchiyama S, Nakagawa T (2008) Phytocomponent p-hydroxycinnamic acid stimulates mineralization in osteoblastic MC3T3-E1 cells. Int J Mol Med 22: 287-291. [Crossref]

28. Lai YL, Yamaguchi M (2007) Phytocomponent $p$-hydroxycinnamic acid inhibits osteoclast-like cell formation in mouse bone marrow cultures. Int J Mol Med 19: 123 128. [Crossref]

29. Yamaguchi M, Weitzmann MN (2009) The bone anabolic carotenoids $p$-hydroxycinnamic acid and $\beta$-cryptoxanthine NF- $\mathrm{kB}$ activation in MC3T3 preosteoblasts. Mol Med Reports 2: 641-644.
30. Yamaguchi M, Weitzmann MN (2012) The bone anabolic carotenoid $p$-hydroxycinnamic acid promotes osteoblast mineralization andsuppresses osteoclast differentiation by

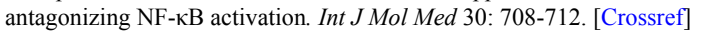

31. Yamaguchi M, Lai YL, Uchiyama S, Nakagawa T (2008) Oral administration of phytocomponent $p$-hydroxycinnamic acid prevents bone loss in ovariectomized rats. Mol Cell Biochem 311: 31-36. [Crossref]

32. Lai YL, Yamaguchi M (2007) Oral administration of phytocomponent $p$-hydroxycinnamic acid has a preventive effect on bone loss in streptozotocin-induced diabetic rats. Int J Mol Med 19:803-807.

Copyright: @2015 Natarajan V. This is an open-access article distributed under the terms of the Creative Commons Attribution License, which permits unrestricted use, distribution, and reproduction in any medium, provided the original author and source are credited. 